University of Wollongong

Research Online

Faculty of Engineering and Information

Faculty of Engineering and Information

Sciences - Papers: Part A

Sciences

$1-1-2015$

Development and optimization of an innovative HVAC system with integrated PVT and PCM thermal storage for a net-zero energy retrofitted house

Massimo Fiorentini

University of Wollongong, mf877@uowmail.edu.au

Paul Cooper

University of Wollongong, pcooper@uow.edu.au

Zhenjun Ma

University of Wollongong, zhenjun@uow.edu.au

Follow this and additional works at: https://ro.uow.edu.au/eispapers

Part of the Engineering Commons, and the Science and Technology Studies Commons

Research Online is the open access institutional repository for the University of Wollongong. For further information contact the UOW Library: research-pubs@uow.edu.au 


\title{
Development and optimization of an innovative HVAC system with integrated PVT and PCM thermal storage for a net-zero energy retrofitted house
}

\begin{abstract}
This paper describes a novel solar-assisted HVAC system developed for the Team UOW 'Illawarra Flame' Solar Decathlon house, the winner of the Solar Decathlon China 2013 competition. This HVAC system consists of an air-based photovoltaic-thermal (PVT) collector and a phase change material (PCM) thermal storage unit integrated with a reverse cycle heat pump, in a ducted system. The system was designed for operation during both winter and summer using daytime solar radiation and night-time sky radiative cooling, respectively. The PVT collector heats or cools fresh air from ambient and thereby provides heating or cooling either directly to the indoor space, or to the PCM storage unit. The heat stored in the PCM can be used later to condition the space or precondition the air entering the air handling unit. Analytical models for the PVT collector and PCM unit were developed in order to be easily implemented into a practical building management system (BMS). Experimental studies on the PVT collector and PCM unit were carried out and the data was used to validate the effectiveness of the models. It is shown that there is a good agreement between the model simulation results and experimental test data. A simple optimisation methodology of the operating modes that involve these components is also presented.
\end{abstract}

\section{Keywords}

optimization, innovative, hvac, system, integrated, pvt, pcm, thermal, development, storage, house, net, zero, energy, retrofitted

\section{Disciplines \\ Engineering | Science and Technology Studies}

\section{Publication Details}

Fiorentini, M., Cooper, P. \& Ma, Z. (2015). Development and optimization of an innovative HVAC system with integrated PVT and PCM thermal storage for a net-zero energy retrofitted house. Energy and Buildings, 94 21-32. 


\title{
Development and Optimization of an Innovative HVAC System with Integrated PVT and PCM Thermal Storage for a Net-Zero Energy Retrofitted House
}

\author{
Massimo Fiorentini*, Paul Cooper, Zhenjun Ma \\ Sustainable Buildings Research Centre (SBRC), Faculty of Engineering and Information \\ Sciences, University of Wollongong, New South Wales, 2522, Australia
}

\begin{abstract}
This paper describes a novel solar-assisted HVAC system developed for the Team UOW 'Illawarra Flame' Solar Decathlon house, the winner of the Solar Decathlon China 2013 competition. This HVAC system consists of an air-based Photovoltaic-Thermal (PVT) collector and a Phase Change Material (PCM) thermal storage unit integrated with a reverse cycle heat pump, in a ducted system. The system was designed for operation during both winter and summer using daytime solar radiation and night-time sky radiative cooling, respectively. The PVT collector heats or cools fresh air from ambient and thereby provides heating or cooling either directly to the indoor space, or to the PCM storage unit. The heat stored in the PCM can be used later to condition the space or precondition the air entering the Air Handling Unit. Analytical models for the PVT collector and PCM unit were developed in order to be easily implemented into a practical Building Management System (BMS). Experimental studies on the PVT collector and PCM unit were carried out and the data was used to validate the effectiveness of the models. It is shown that there is a good agreement between the model simulation results and experimental test data. A simple optimisation methodology of the operating modes that involve these components is also presented.
\end{abstract}

Keywords: Solar-assisted HVAC system; Photovoltaic-thermal; Phase change material; Thermal modelling; Experimental validation

*Corresponding Author:_email:mf877@uowmail.edu.au_phone:+610421918240 address: Sustainable Buildings Research Centre (SBRC)

Building 237, Innovation Campus, Squires Way, North Wollongong, NSW 2500, Australia 


\section{Introduction}

Every year only approximately 1 to 2 percent of the Australian residential building stock is replaced by or added to by new buildings [1]. Many of the houses built in Australia after the Second World War were timber-framed houses, clad in fibre-cement and were hence colloquially named 'fibro' houses. These buildings typically have little or no thermal insulation and generally exhibit poor thermal performance and low energy efficiency. Under the auspices of the University of Wollongong (UOW) Sustainable Buildings Research Centre (SBRC) a student/staff team (Team UOW) was formed with the members drawn from both the University of Wollongong and TAFE (Technical and Further Education) NSW (New South Wales) Illawarra Institute. Team UOW set out to be the first team in the history of Solar Decathlon competitions to demonstrate how to effectively upgrade and retrofit an existing building rather than designing a new building from scratch. This approach proved to be extremely successful and Team UOW subsequently won the Solar Decathlon China 2013 competition with the highest overall score in the history of Solar Decathlon competitions, which have run in the USA, Europe and China since 2002. Team UOW decided to develop a retrofitting strategy to demonstrate how to improve the level of thermal comfort and overall sustainability performance of a 'fibro' home through the development and application of different retrofit technologies. One of the key targets was to achieve net-zero energy consumption in that the grid-connected building was to generate more renewable energy onsite than that it imports from the grid over the course of a year. To achieve this target, it is first necessary to reduce the energy demand of the building through the implementation of effective passive retrofitting initiatives, such as upgrading the envelope, glazing and shading systems, using natural ventilation, etc. followed retrofitting and application of advanced active systems. 
The development and implementation of an innovative HVAC system incorporating advanced sustainable energy technologies was a desired outcome of the project. Solar photovoltaic-thermal (PVT) collectors were seen as a promising technology that was receiving wide attention. Cooling of the PV modules by the heat transfer fluid flowing through the PVT collector then leads to an increase in the electrical efficiency of the PV panels as compared to a conventional PV system which has higher PV cell operating temperatures. At the same time, heat transferred to or from the fluid may be used for space heating or cooling, thereby resulting in an increase in the overall energy collection and conversion efficiencies of the system.

Phase change materials (PCMs) generally have a high energy storage density and the capability to store thermal energy at a relatively constant temperature, which has been recognized as a sustainable and environmentally friendly technology to reduce building energy consumption and improve indoor thermal comfort [2, 3]. Coupling PCMs with solar collectors may provide an alternative to attempting to increase the efficiency of traditional HVAC systems. Such integrated systems have been investigated since the 1970s and studies have been performed on the evaluation of the performance of air heaters coupled with PCM thermal storage units [4], determination of the thermal properties of the PCMs used [5] and sizing of the thermal storage units [6]. More recent bibliographic studies have shown that PCM thermal storage systems are a widely investigated technology and a rapidly developing research area [7, 8]. PCMs have been studied over the past years in both passive and active systems [2, 3] and a number of research groups have investigated PVT systems coupled with ventilated slabs for energy storage $[9,10]$. Studies on the effectiveness of PVT collectors during daytime heating and night-time radiative cooling have been undertaken, for both water-based and air-based systems [10-12]. 
This paper focusses on the development and modelling of an innovative solar PVTassisted Heating, Ventilation and Air Conditioning (HVAC) system integrated with a PCM thermal energy storage unit. The main objective of the work described herein was to develop theoretical models which can accurately predict the heat transfer rates in an air-based PVT collector and a PCM thermal storage unit, the mechanical losses in both components, and the electrical output from the PVT collector. The model has a relatively simple structure with a low computational overhead and so that it can be easily implemented into the optimization strategies of commercial Building Management Systems (BMSs).

\section{Development of the Innovative HVAC System}

The Team UOW 'Illawarra Flame' Solar Decathlon house and a schematic of the HVAC developed in this project are shown in Figures 1 and 2, respectively. The HVAC system consisted of an air-based PVT collector (shown on the left hand side of the roof in Figure 1), a PCM thermal energy storage unit, and a standard reverse cycle air-conditioning system, using a ducted air distribution system and dampers to regulate the airflow within the system.

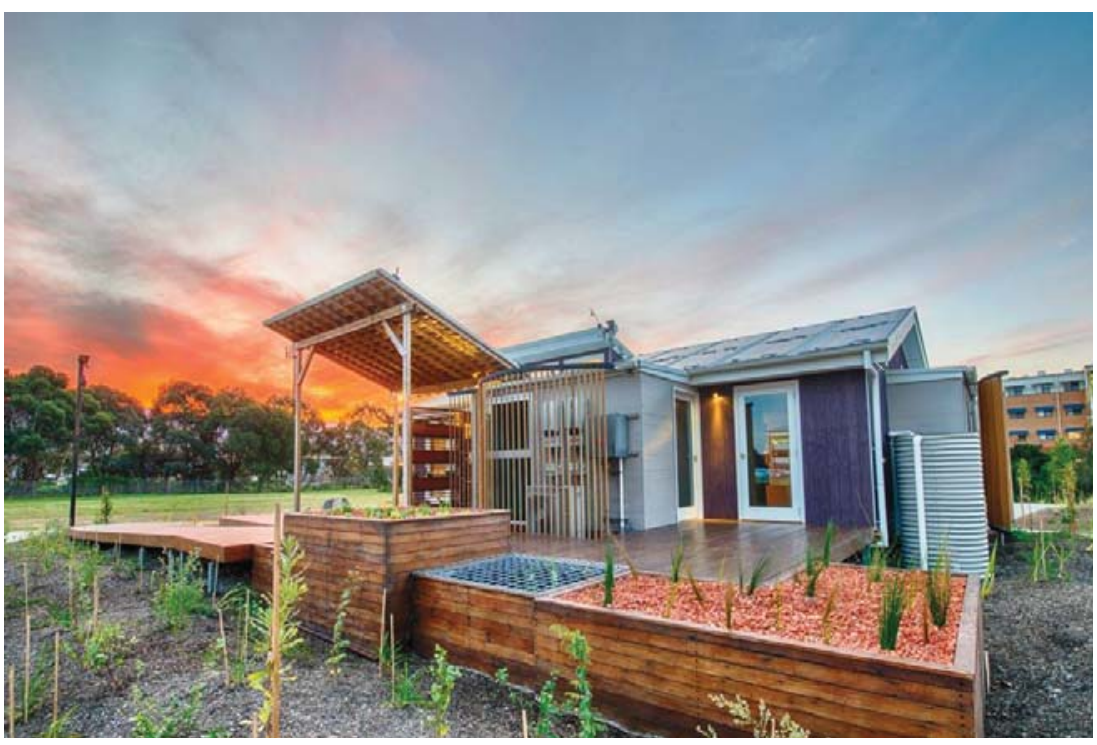

Figure 1: Team UOW 'Illawarra Flame' Solar Decathlon house located at the University of Wollongong Innovation Campus. 
The use of air in the PVT collector as a working fluid was chosen to facilitate retrofitting of an existing house, with features including low maintenance requirements and the ability to integrate with conventional ducted air-conditioning systems. The PVT collector was fabricated from flexible thin-film CIGS PV panels glued to a metal flashing fixed across the 'valleys' of the roof sheeting. Air could therefore flow through the air duct between the PV panels/flashing and the roof sheeting to exchange heat with the panels.

The diurnal phase of the thermal energy generated from the PVT collector has a significant offset as compared to thermal demand of the building, for Sydney weather conditions. For this reason an active thermal storage unit was included, and a PCM has been selected as the preferred storage material. A number of types of PCMs were available on the market, each with different thermal properties and phase change temperatures, and for the present system a salt hydrate mixture with a phase change temperature of $22^{\circ} \mathrm{C}$ was selected, supplied in plastic containers. To ensure the system always meet the energy demand of the house and maintain good indoor thermal comfort, a standard reverse cycle air-conditioning system with an outdoor condensing unit and an indoor air handling unit (AHU) was integrated into the system.

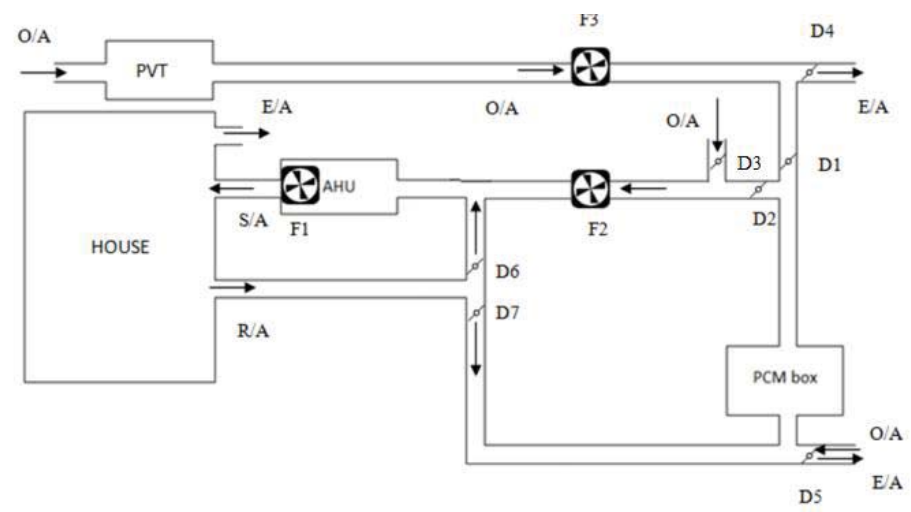

$$
\begin{aligned}
& \text { S/A = Supply Air } \quad \mathrm{O} / \mathrm{A}=\text { Outside } \text { air } \quad \mathrm{R} / \mathrm{A}=\text { Return air } \\
& \text { E/A= Exhaust air } \quad \mathrm{F}=\text { Fan } \quad \mathrm{D}=\text { Damper }
\end{aligned}
$$

Figure 2: Schematic of the solar-assisted HVAC system where the symbols represent the following: S/A supply air, O/A outside air, R/A return air, E/A exhaust air, $\mathrm{F}$ fan and D damper, respectively 
The system was controlled by a residential control system with a programmable logic controller. This paper focuses mainly on the development and validation of the analytical models of the PVT collector and the PCM thermal storage unit and the utilisation of these models for the optimisation of the various operating modes of the HVAC system.

There are a total of five operating modes, including three conditioning modes and two PVT modes, in this HVAC system, which will be controlled through the BMS system specifically designed for this project.

\section{$\underline{\text { Conditioning modes }}$}

Figure 3 presents the different operating modes that the system can operate based on the indoor and outdoor measured conditions. Depending on the indoor conditions, the system can either work in natural ventilation mode through automatically controlling the opening of high level windows, or work in forced mechanical heating and cooling mode.

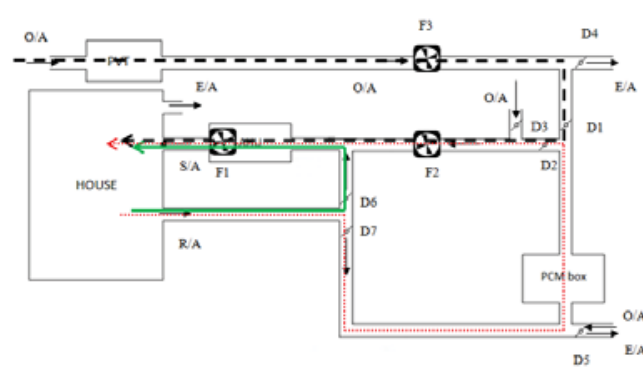

- Diret PVT Supply
- Normal conditioting mode
-
D5 $\quad$ EA

a)

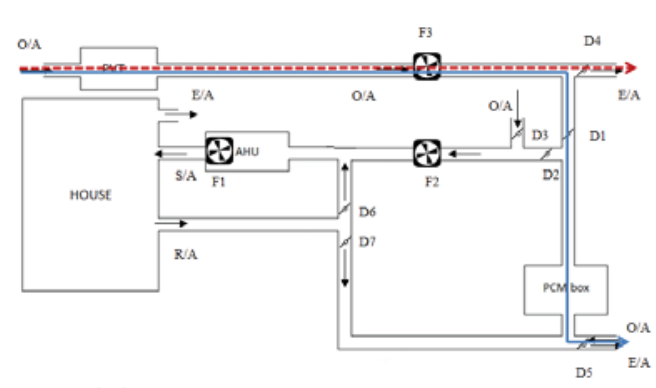

- PCM Charging

b)

Figure 3: Illustration of a) HVAC system conditioning modes and b) HVAC system PVT

modes.

In the mechanical heating and cooling mode, the system can operate in three different sub-modes, as illustrated in Figure 3a.

1. Direct Photovoltaic-Thermal Supply. If the generation of heating during daytime or cooling during night time (night sky radiative cooling) occurs at the same time as the 
demand, then heated air/cooled air from the PVT system is directed into the house until the demand is matched. If the demand is higher than the energy extracted from the PVT system, the AHU will cover the remaining heating/cooling requirement.

2. Supply Air Preconditioned Through Phase Change Material. In this case, if thermal energy is available in the PCM store the mixture of return air and fresh air will be preconditioned by the PCM store, increasing or decreasing the supply air temperature. If the demand is higher than the energy extracted from the PCM storage unit, the AHU will cover the remaining heating/cooling requirement.

3. Normal Heating and Cooling Mode. If there are no PVT thermal generation and no thermal energy stored in the PCM, the AHU will supply the heating or the cooling required.

\section{$\underline{P V T \text { modes }}$}

If no interfering operating mode is activated, the system can operate in two other modes, as shown in Figure 3b.

1. PCM Charging. If there are no demand from the house, and the PCM unit is not fully charged as well as it is convenient to charge it, the PVT system will charge the PCM unit.

2. PVT Exhaust. In case the increase in electrical generation of the solar panels due to their temperature decrease is higher than the energy used by the fan, the air can be drawn underneath the PV panels and exhausted directly to ambient.

\section{Analytical Model of the PVT Collector}

The PVT collector studied in this paper consisted of a number of thin-film PV panels mounted on a steel sheet 'flashing', which was fixed to the top of an existing sheet metal roof profile. This system created a cavity beneath the steel flashing through which the working 
fluid (i.e. air) can flow through and exchange heat with the PV panel, as shown schematically in Figure 4.

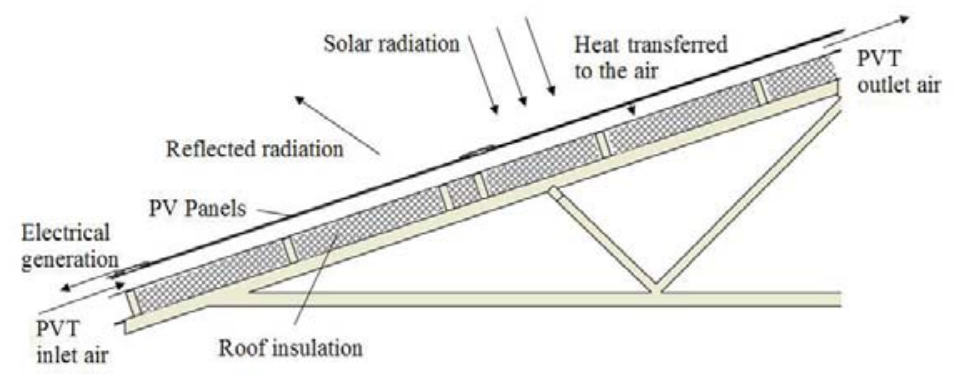

a) Day time generation

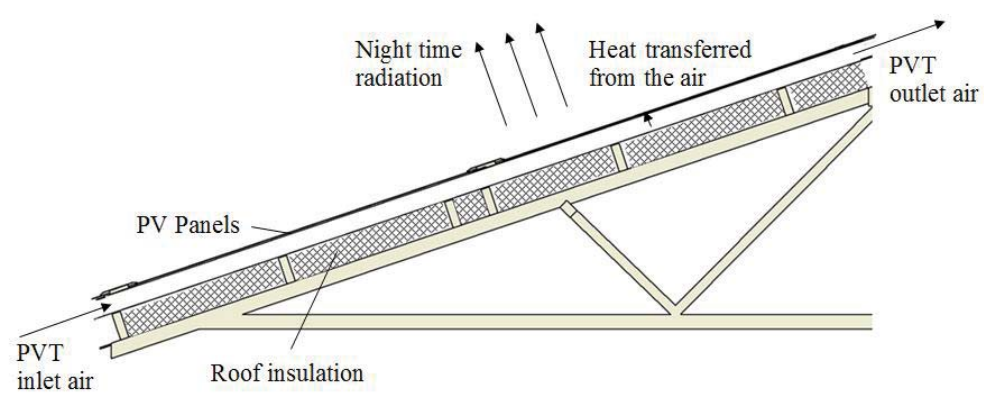

b) Night time generation

Figure 4: Overview of the PVT collector geometry as implemented on the Illawarra Flame Solar Decathlon House.

The utilisation mode of the PVT collector generally depends on the demand of the house. For instance, when heating is required in winter daytimes, the incoming solar radiation generates electricity through the PV modules. Part of the radiation is reflected/reradiated, part is lost to ambient via convection and the remainder is transferred to the heat transfer fluid (Figure 4a). The air mass flow rate is the key parameter that allows the Building Management System to control the air temperature at the outlet of the PVT collector and also the quantity of heat extracted from the PV modules.

Under Sydney summer conditions the house would mainly require cooling. In this case the PVT will generate cooling during the night time, whereby the solar panels extract heat 
from the air flowing through the PVT collector by emitting radiation to the sky if the sky is at a lower temperature than the panels (See Figure $4 \mathrm{~b}$ ).

So as to maximise the use of available roof space for PV electrical generation during the Solar Decathlon China 2013 competition, the PVT collector was designed so as to draw air from both the north and south elevations of the pitched roof and the two air streams then mixed in a plenum at the apex of the roof as shown in Figure 5.

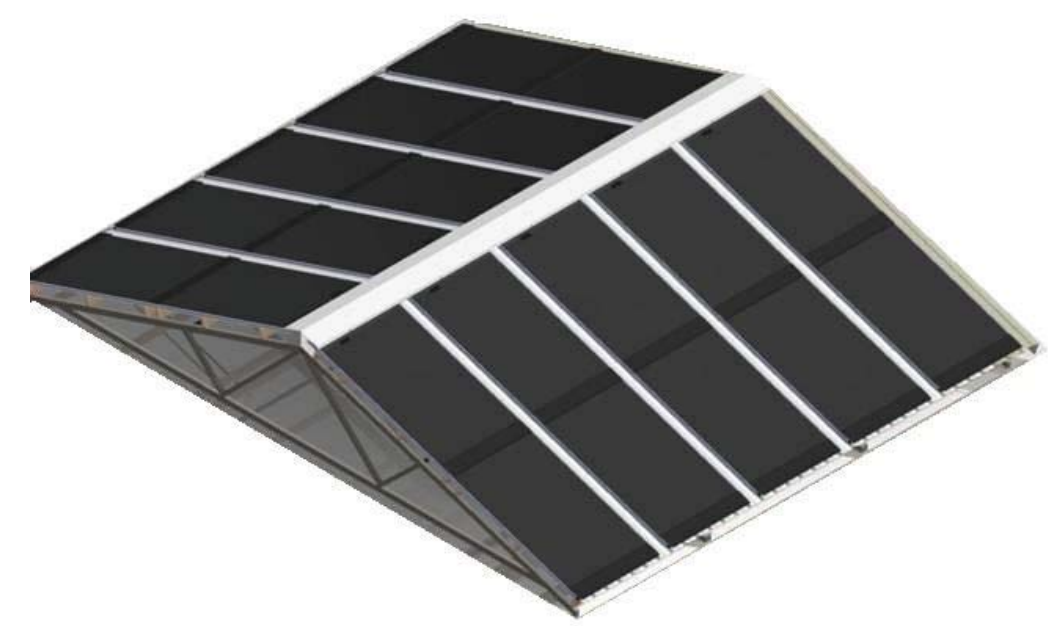

Figure 5: Photovoltaic thermal (PVT) collectors implemented on the roof of the Illawarra Flame Solar Decathlon house.

To optimize the system and calculate the optimal airflow rate, it is necessary to accurately model the heat transfer into the air channels below the PV modules, the mechanical losses in the system, and the electrical benefit of reducing the temperature of the PV panels.

\subsection{Thermal model}

An analytical steady state model was developed to describe the thermal behaviour of the PVT collector. This model can be used for both design optimisation and control optimisation purposes. The key assumptions used in developing this quasi-steady state model were that: a) 
the transients involved in heating or cooling of the system are relatively short compared to the time constants elsewhere in the building and HVAC system; and b) that the conduction resistance through the upper and lower walls of the air duct are negligible in comparison to the other convection, conduction and radiation thermal resistances. These assumptions can be justified by the fact that the thin metal flashing and the thin film solar panels have relatively low thermal mass and thermal resistance (our experimental results indicated that the thermal time constant of the PVT collectors was less than five minutes).

Taking an energy balance on a short, stream-wise control volume in the PVT collector air duct, an analytical solution for the thermal performance of the collector may be derived; the thermal resistance network for heat flow at a given cross-section of the PVT collector/duct is illustrated in Figure 6.

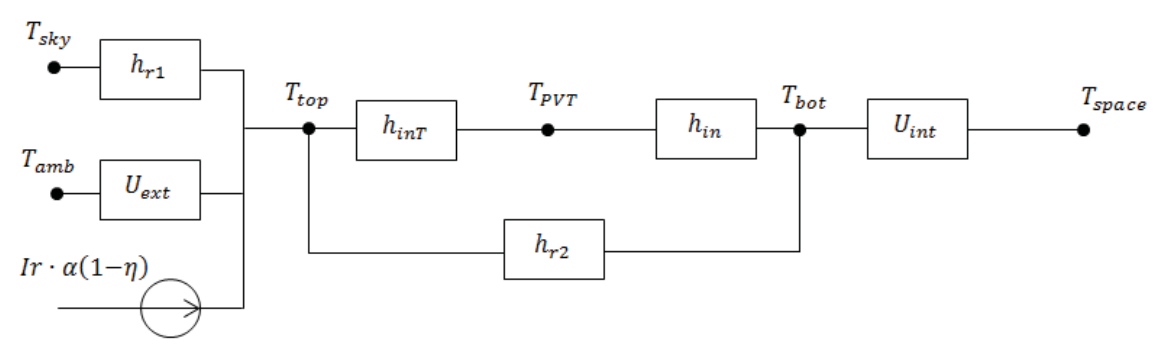

Figure 6: Thermal resistance network model of the heat exchange at a given crosssection of the PVT collector.

The energy balance on the upper and lower surfaces of the PV panel, the energy balance on the air flowing into and out of the control volume, and the heat balance on the lower surface of the duct may be described by (3.1), (3.2) and (3.3), respectively.

$$
\begin{aligned}
& I r \cdot \alpha(1-\eta)=U_{\text {ext }}\left(T_{\mathrm{top}}-T_{\mathrm{amb}}\right)+h_{\mathrm{r} 1}\left(T_{\mathrm{top}}-T_{\mathrm{sky}}\right)+\bar{h}_{\mathrm{inT}}\left(T_{\mathrm{top}}-T_{P V T}\right)+h_{\mathrm{r} 2}\left(T_{\mathrm{top}}-T_{\mathrm{bot}}\right) \\
& \dot{V} \cdot \rho \cdot c_{p} \cdot \frac{\partial T_{P V T}}{\partial x} d x=\left[\bar{h}_{\text {inT }}\left(T_{\text {top }}-T_{P V T}\right)+\bar{h}_{\text {in }}\left(T_{b o t}-T_{P V T}\right)\right] \cdot w \cdot d x \\
& \bar{h}_{\mathrm{in}}\left(T_{P V T}-T_{\mathrm{bot}}\right)=U_{\mathrm{int}}\left(T_{\mathrm{bot}}-T_{\text {space }}\right)+h_{\mathrm{r} 2}\left(T_{\mathrm{bot}}-T_{\mathrm{top}}\right)
\end{aligned}
$$


Where $\dot{V}$ is the volumetric air flow rate, $\rho$ and $c_{p}$ are the density and specific heat capacity of the air, $T_{P V T}$ is the local air temperature in the PVT channel, $T_{\text {top }}$ and $T_{b o t}$ are the temperatures of the top and bottom plates of the PVT channel, $\bar{h}_{i n}$ and $\bar{h}_{i n T}$ are the average heat transfer coefficients on the bottom and top inside surfaces of the channel, respectively, $U_{\text {int }}$ is the overall heat transfer coefficient between the bottom plate of the PVT channel and indoor environment, $U_{\text {ext }}$ is the overall convective heat transfer coefficient between the top plate of the PVT channel and ambient, $h_{r 1}$ is the radiative heat transfer coefficient between the outside surface of the PV panel and the sky, $h_{r 2}$ is the radiative heat transfer coefficient between the duct top and bottom surfaces, $x$ and $w$ are the length and the width of the channel, respectively, $T_{\text {sky }}$ is the temperature of the sky and $T_{\text {space }}$ is the interior building temperature. Combining (3.1) and (3.3), the top and bottom surface temperatures of the PVT duct can be determined from (3.4) and (3.5), respectively.

$$
\begin{aligned}
& T_{\text {top }}=\frac{\left(\bar{h}_{i n}+h_{r 2}+U_{i n t}\right)\left(\left(U_{\text {ext }}+\bar{h}_{i n T}+h_{r 1}+h_{r 2}\right)\left(T_{P V T} \bar{h}_{i n}+U_{i n t} T_{s p a c e}\right)+I r \alpha h_{r 2}(1-\eta)+U_{e x t} h_{r 2} T_{a m b}+T_{P V T} \bar{h}_{i n T} h_{r 2}+h_{r 1} h_{r 2} T_{s k y}\right)}{h_{r 2}\left(\left(\bar{h}_{i n}+h_{r 2}+U_{i n t}\right)\left(U+\bar{h}_{i n T}+h_{r 1}+h_{r 2}\right)-h_{r 2}{ }^{2}\right)}- \\
& \frac{T_{P V T} \bar{h}_{i n}+U_{\text {int }} T_{\text {space }}}{h_{r 2}} \\
& T_{\text {bot }}=\frac{\left(U_{\text {ext }}+\bar{h}_{i n T}+h_{r 1}+h_{r 2}\right)\left(T_{P V T} \bar{h}_{i n}+U_{i n t} T_{\text {space }}\right)+I r \alpha h_{r 2}(1-\eta)+U_{e x t} h_{r 2} T_{a m b}+T_{P V T} \bar{h}_{i n T} h_{r 2}+h_{r 1} h_{r 2} T_{s k y}}{\left(\bar{h}_{i n}+h_{r 2}+U_{i n t}\right)\left(U+\bar{h}_{i n T}+h_{r 1}+h_{r 2}\right)-h_{r 2}{ }^{2}}
\end{aligned}
$$

It is then possible to recast $T_{\text {top }}$ and $T_{\text {bot }}$ as follows:

$T_{\text {top }}=C 1 T_{P V T}+C 2$

$T_{\text {bot }}=C 3 T_{P V T}+C 4$

where, C1, C2, C3 and C4 are coefficients and defined as follows:

$$
\begin{aligned}
& C 1=\frac{\left(\bar{h}_{i n}+h_{r 2}+U_{i n t}\right) C 3}{h_{r 2}}-\frac{\bar{h}_{i n}}{h_{r 2}} \\
& C 2=\frac{\left(\bar{h}_{i n}+h_{r 2}+U_{i n t}\right) C 4}{h_{r 2}}-\frac{U_{i n t} T_{\text {space }}}{h_{r 2}} \\
& C 3=\frac{\left(U_{\text {ext }}+\bar{h}_{i n T}+h_{r 1}+h_{r 2}\right) \bar{h}_{i n}+\bar{h}_{i n T} h_{r 2}}{\left(\bar{h}_{i n}+h_{r 2}+U_{i n t}\right)\left(U_{\text {ext }}+\bar{h}_{i n T}+h_{r 1}+h_{r 2}\right)-h_{r 2}{ }^{2}}
\end{aligned}
$$


$C 4=\frac{\left(U_{e x t}+\bar{h}_{i n T}+h_{r 1}+h_{r 2}\right)\left(U_{i n t} T_{s p a c e}\right)+I r \alpha h_{r 2}(1-\eta)+U_{e x t} h_{r 2} T_{a m b}+h_{r 1} h_{r 2} T_{s k y}}{\left(\bar{h}_{i n}+h_{r 2}+U_{i n t}\right)\left(U_{\text {ext }}+\bar{h}_{i n T}+h_{r 1}+h_{r 2}\right)-h_{r 2}{ }^{2}}$

Combining (3.11) and (3.2) we then derive:

$\frac{\partial T_{f}}{\partial x} d x=\frac{w}{\dot{V} \cdot \rho \cdot c_{p}}\left[\left(\bar{h}_{i n} C 2+\bar{h}_{i n T} C 4\right)+T_{f}\left(\bar{h}_{i n T} C 1+\bar{h}_{i n} C 3-\left(\bar{h}_{i n}+\bar{h}_{i n T}\right)\right)\right]$

Equation (3.12) is a first order, nonhomogeneous, linear differential equation with constant coefficients, of the form expressed in (3.13) with the general solution of (3.14).

$y^{\prime}+a y=b \quad y=y(x)$

$y=\bar{y}+y^{*}=C e^{-a x}+\frac{b}{a}$

From (3.12) we can then derive (3.15):

$\left\{\begin{array}{c}T_{P V T}{ }^{\prime}+A T_{P V T}=B \\ T_{P V T}(0)=T_{a m b}\end{array}\right.$

The solution of which is:

$T_{P V T}=\left(T_{a m b}-\frac{B}{A}\right) e^{-A x}+\frac{B}{A} \quad$.

Where

$A=-\frac{w}{\dot{V} \cdot \rho \cdot c_{p}}\left(\bar{h}_{i n T} C 1+\bar{h}_{i n} C 3-\left(\bar{h}_{i n}+\bar{h}_{i n T}\right)\right)$
$B=\frac{w}{\dot{V} \cdot \rho \cdot c_{p}}\left(\bar{h}_{i n} C 2+\bar{h}_{i n T} C 4\right)$

The convective heat transfer coefficient on the upper/outside surface of the PVT is dependent on the local wind speed $(V w)$ and is calculated from the correlation (3.19) by considering both the natural and forced convection components through the following relationship [12], in which the forced convection heat transfer coefficient $h_{\text {conv,forced }}$ is determined by Equation (3.20) [17].

$U_{\text {ext }}=\sqrt[3.5]{h_{\text {conv,forced }}^{3.5}+h_{\text {conv,natural }}^{3.5}}$ 
$h_{\text {conv }, \text { forced }}=2.8+3.0 * w s$

The natural convection coefficient on the upper surface of the PVT is calculated according to the relationships of ASHRAE 2009 Fundamentals Handbook correlations for natural convection on a horizontal plate [15].

The internal convective heat transfer coefficient $\left(\bar{h}_{i n}\right)$ within the duct is dependent on the Reynolds number, which is different for laminar flow and turbulent flow. The heat transfer coefficient of the top half of the PVT channel $\left(\bar{h}_{i n T}\right)$ also includes the thermal resistance of the PV panels:

$\bar{h}_{i n T}=\frac{1}{\frac{1}{h_{i n}}+R_{p v}}$

In this model, when the Reynolds number is lower than 2000, Equation (3.22) is used to calculate the Nusselt number. Otherwise, the Dittus-Boelter relationship for turbulent flow as shown in Equation (3.23) is used.

$$
\begin{aligned}
& N u_{l}=7.541\left(1-2.61 A R+4.97 A R^{2}-5.119 A R^{3}+2.702 A R^{4}-0.548 A R^{5}\right) \\
& N u_{t}=0.023 \operatorname{Pr}^{n} R^{\frac{4}{5}}
\end{aligned}
$$

where, $A R$ is the aspect ratio (height/width) of the channel, $\operatorname{Pr}$ is the Prandtl number of air and $n$ is equal to 0.4 when the airflow is heated and 0.3 when the airflow is cooled.

The parameters needed to calculate the instantaneous intensity of solar radiation impinging on a tilted surface are summarised in Table 1.

Table 1 Values and governing equations used to determine the values of major parameters.

\begin{tabular}{|l|l|}
\hline Parameters & Values and governing equations used \\
\hline Albedo & 0.2 \\
\hline Hour Angle & $\omega=2 \pi(\operatorname{stn}-12) \cdot 15 / 360$ \\
\hline Declination & $d=23.45 \cdot \sin (360 \cdot(284+d o y) / 365) \cdot 2 \pi / 360$ \\
\hline The angle $\theta$ between the normal & $\cos \theta=\sin d \sin \varphi \cos \beta-\sin \delta \cos \varphi \sin \beta \cos \gamma+$ \\
\hline
\end{tabular}




\begin{tabular}{|l|l|}
\hline $\begin{array}{l}\text { to the inclined plane and the } \\
\text { beam radiation }\end{array}$ & $\begin{array}{l}\cos \delta \cos \varphi \cos \beta \cos \omega+\cos \delta \sin \varphi \sin \beta \cos \gamma \cos \omega+ \\
\cos \delta \sin \beta \sin \gamma \sin \omega\end{array}$ \\
\hline $\begin{array}{l}\text { The radiation on an inclined } \\
\text { surface }\end{array}$ & $\begin{array}{l}G_{\text {inclined }}=D n r \cos \theta+\frac{D h r(1+\cos \beta)}{2}+0.2(G h r+ \\
D h r)(1-\cos \beta) / 2\end{array}$ \\
\hline
\end{tabular}

In cases where only site data for global horizontal radiation is available, the horizontal surface radiation measurement can be used to estimate the diffuse and beam components. The coefficient $R_{b}$ is used to define the ratio of beam radiation on the tilted surface to that on a horizontal surface.

$R_{b}=\frac{\cos \theta}{\cos \theta_{z}}$

where, $\theta_{z}$ is the angle $\theta$ calculated for a horizontal surface as follows.

$\cos \theta_{z}=\cos \varphi \cos \delta \cos \omega+\sin \varphi \sin \delta$

The ratio between the diffused and beam radiation is calculated using the Orgill and Hollands correlation [17].

The effective emissivity of the solar panels may be calculated using empirical or semiempirical correlations available in the literature $[12,16]$. Most of which are valid only for clear sky conditions [16], and while factors to take into account of cloudy conditions may be added [18]. The temperature of the sky in this study was calculated using the relationship for night-time clear sky radiation provided by Duffie and Beckman, as follows [17]:

$$
T_{s k y}=T_{a m b} *\left(0.711+0.0056 T_{d p}+0.000073\left(T_{d p}^{2}\right)+0.013 \cos (15 t)\right)^{1 / 4}
$$

Where the units for $T_{s k y}$ and $T_{a m b}$ are Kelvin, for $T_{d p}$ degrees Celcius, and $t$ is the time of day in hours.

Cloudiness has an effect on the incident radiation which can be expressed by the factor $C$ as shown in Equation $(3.27)[18,19]$ and the effective emissivity of the sky is given by (3.28). 
$C=\left(1+0.00224 n+0.0035 n^{2}+0.00028 n^{3}\right)$

$\varepsilon_{\text {sky, cloudy }}=C \varepsilon_{\text {sky, clear }}$

The linearized radiation heat transfer coefficient between the sky and the PV panels is defined as (3.29). Using the same methodology the radiation coefficient between the top plate and bottom plate of the PVT channel is derived as Equation (3.30).

$h_{r 1}=\alpha \sigma\left(T_{t o p}^{2}+T_{s k y}^{2}\right)\left(T_{t o p}+T_{s k y}\right)$

$h_{r 2}=\alpha \sigma\left(T_{t o p}^{2}+T_{b o t}^{2}\right)\left(T_{t o p}+T_{b o t}\right)$

where, $\sigma$ is the Boltzmann constant, $\alpha$ is the absorptivity of the metal flashing, $T_{s k y}$ is the sky temperature, and $T_{\text {top }}$ is the temperature of the top plate of the PVT channel, which is calculated iteratively.

\subsection{Airflow model}

To optimize the airflow rate through a PVT collector it is necessary to take into account the fan power required to circulate the air through the PVT and ductwork system. Firstly, the air velocity through the PVT channels, and other ductwork, and the associated pressure drops need to be calculated. To calculate these parameters an equivalent hydraulic resistance network was analysed (Figure 7). 


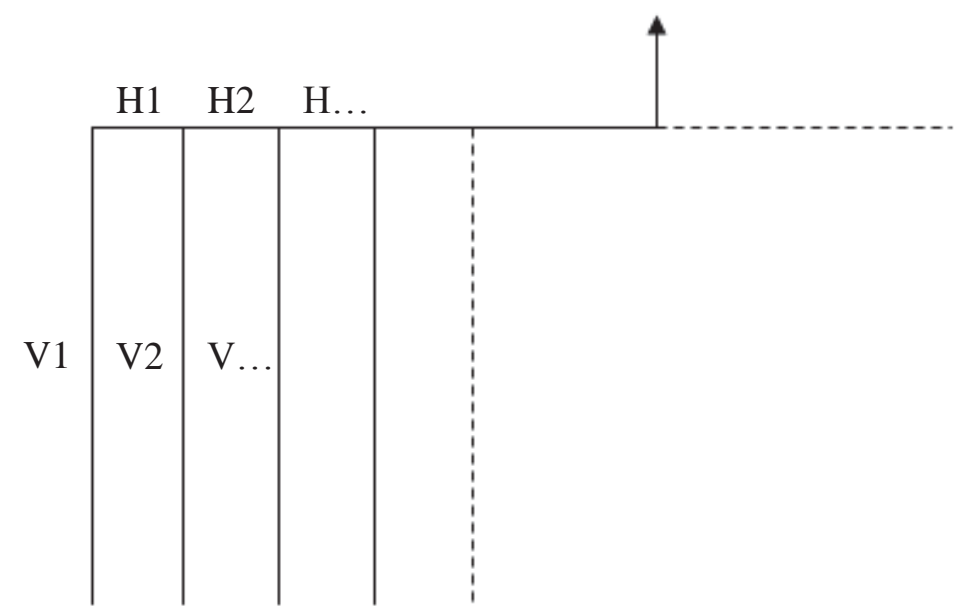

Figure 7: Air flow resistance network showing flow elements/resistances for flow branches connected to the air collection manifold. V1, V2, etc. represent PVT ducts and $\mathrm{H} 1, \mathrm{H} 2$, etc. represent manifold sections.

This analysis was important in choosing the optimal number and size of the PVT channels and in optimising the geometry of the manifold, since a uniform air flow velocity through the PVT channels is important to maximise the overall efficiency.

One of the assumptions made in this model is that, since the channels are uniformly distributed across the intake manifold, the flows will be symmetrical, and it is therefore necessary to model only one half of the system. Major and minor losses are calculated for each of the sections of the network by first assuming the flow in the first channel it is then possible to calculate the pressure at the manifold point where the second channel is connected and therefore calculate the flow in the second channel. Repeating the process the pressure drop of the whole network for a given airflow rate, and the flow distribution across the network can be obtained. The pressure-airflow curve for this particular system can then be determined. Since both sides of the roof are equal and symmetrical, the curve of just one side can be generated, assuming that each side of the PVT has half of the total airflow rate. The power necessary to ideally circulate the air through the system can then be calculated by Equation (3.31). 
$P_{i d}=\Delta p \cdot \dot{V}$

where $\Delta p$ is the total pressure drop and $\dot{V}$ is the total airflow rate.

With a cubic interpolation of Equation (3.32), a relationship that can be used later for optimization purposes that can include the overall efficiency of the fan.

$$
P_{e, \text { cons }}=P_{i d} / \eta=\gamma_{P V T} \dot{\mathrm{V}}^{3}
$$

The pressure-airflow rate curve calculated for the Solar Decathlon house PVT system is shown in Figure 8.

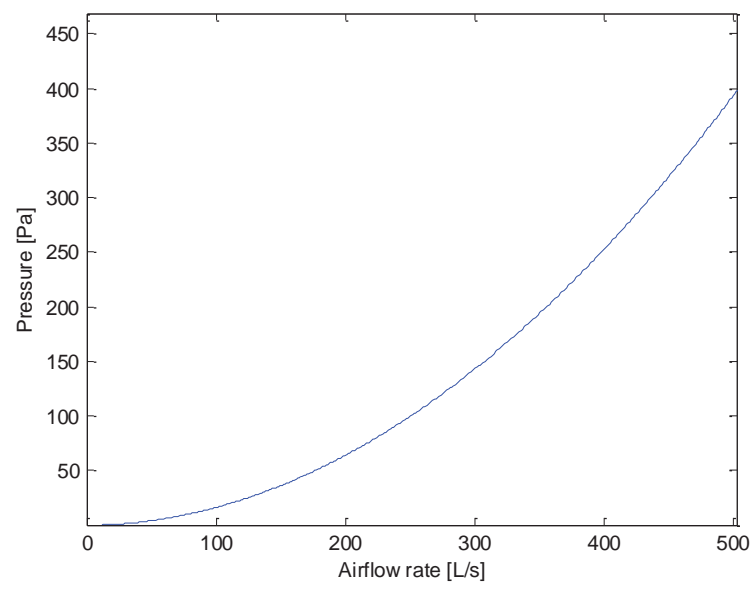

Figure 8: Pressure-airflow characteristic of the 'Illawarra Flame' Solar Decathlon house PVT collector.

\subsection{PV electrical efficiency}

Drawing air underneath the solar panels has the benefit of reducing the panel temperature as described by [19] and a reduction in the temperature of the solar panels increases their electrical conversion efficiency. This benefit can be quantified using the temperature coefficient of the solar panels, $\beta$. Using the thermal model developed for the air stream, presented in section 3.1, the temperature profile of the top sheet of the PVT collector $\left(T_{\text {top }}\right)$ can be calculated. The efficiency is therefore given by Equation (3.33).

$\eta_{e}=\eta_{e-r e f} \cdot\left(1-\beta \cdot\left(T_{t o p}-25\right)\right)$ 
where $\eta_{e-r e f}$ is the efficiency under standard test conditions.

\section{Analytical Model of the PCM Thermal Storage Unit}

The PCM thermal storage unit in the Solar Decathlon house was designed to exchange heat between the PCM and the air. The practical PCM thermal storage unit consisted of 120 PlusIce ${ }^{\mathrm{TM}}$ salt hydrate PCM 'bricks'[13], with a nominal phase change temperature of $22^{\circ} \mathrm{C}$, placed in twenty rows of six so as to create channels for the air to flow through. The channels were $3 \mathrm{~m}$ long and the latent heat capacity of the whole unit was $20 \mathrm{kWh}$, sufficient for approximately two days of heating or cooling demand of the house.

\subsection{Thermal Model}

A number of assumptions were applied so as to facilitate derivation of an analytical solution to reduce the computational load of the controller. These assumptions were:

- $\quad$ The temperature of the PCM is uniform along the entire length of the heat exchanger at any given time (lumped mass approximation);

- $\quad$ The PCM material changes phase at a specific temperature (with no temperature 'glide');

- $\quad$ The material encapsulating the PCM brick has the same thermal conductivity as that of the PCM material per se. Note that in the Solar Decathlon house thermal store, the encapsulation was made of High-density polyethylene (HDPE) which had a very similar thermal conductivity to that of the PCM.

Given the assumptions above the air temperature as a function of distance along each channel is given by:

$T_{P C M, m}=T_{p c m}-\left(T_{p c m}-T_{P C M, i}\right) e^{\left(-\frac{P \bar{h} x}{\dot{V} \cdot \rho \cdot c p}\right)}$

where $T_{P C M, m}$ is the average temperature of the air at a distance $x$ along the channel, $T_{p c m}$ is the surface temperature of the channel (assumed equal to the PCM temperature), $T_{P C M, o}$ is the 
inlet air temperature, $P$ is the perimeter of the channel, $\bar{h}$ is the average internal convective heat transfer coefficient.

Similarly, the outlet temperature at the length $l$ can be determined by Equation (4.2).

$T_{P C M, o}=T_{p c m}-\left(T_{p c m}-\left(T_{p c m}-T_{P C M, i}\right)\right) e^{\left(-\frac{P \bar{h} l}{\dot{V} \cdot \rho \cdot c p}\right)}$

The average internal convective heat transfer coefficient can be calculated using the Nusselt number definition.

$\bar{h}=\frac{k \overline{N u}}{D_{h}}$

The correlations to evaluate the average Nusselt number for a fully developed laminar flow in a rectangular duct are the same as those presented in (3.22) and (3.23).

To include the thermal resistance of the wall and PCM material in the modelling, it is possible to rewrite the equation with the total heat transfer coefficient $\left(U_{t o t}\right)$.

$R_{\text {conv }}=1 / \bar{h}$

$R_{\text {cond }}=\frac{1}{U_{\text {wall }+P C M}}$

$U_{\text {tot }}=\frac{1}{R_{\text {cond }}+R_{\text {conv }}}$

This coefficient in Equation (4.6) has to be substituted by Equations (4.1) and (4.2) to $\bar{h}$.

The total heat transfer can be calculated as follows:

$Q=\dot{m} c_{p}\left(T_{\text {in }}-T_{\text {out }}\right)$

\subsection{Mechanical analysis}

As for the PVT collector it is necessary to take into account the power required to drive the air through the PCM thermal store. The material in contact with the air in this case is plastic, with a roughness $\varepsilon$ [15]. Figure 9 shows the pressure-airflow curve. Following the same methodology presented in Section 3.2, including the efficiency of the fan, the resulting $3^{\text {rd }}$ order fit for the power consumption is of the same form: 
$P_{e, \text { cons }}=\gamma_{P C M} \dot{\mathrm{V}}^{3}$

This relationship will be used later for system optimization. The pressure-airflow rate curve of the PCM thermal energy storage unit implemented in the Solar Decathlon house is presented in Figure 9.

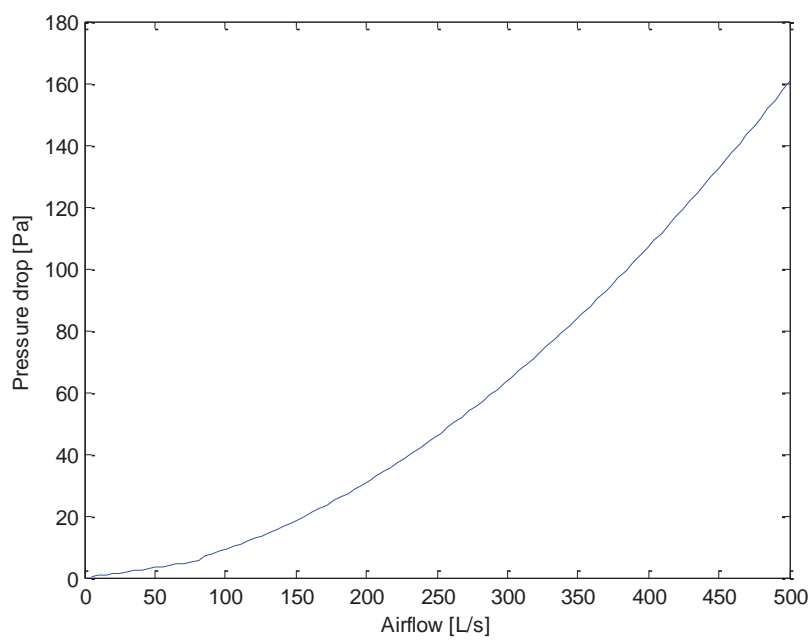

Figure 9: Pressure drop-airflow through the PCM thermal storage unit.

\section{Field Tests and Validation}

In this section the results from both experiments and simulations are presented. The PVT and PCM models were implemented in Matlab and the response of the two sided collector was simulated. For some of these simulations, Sydney IWEC (International Weather for Energy Calculations) weather data was used.

The models were then validated using the experimental data collected in both Datong, China, during the Solar Decathlon China competition and later at the University of Wollongong following the return of the Illawarra Flame House to Australia.

\subsection{Experimental Facilities}

The PVT tests were first carried out during August 2013 in Datong, China, and then in Wollongong, Australia, from June 2014 onwards. The PVT collector, integrated with the 
HVAC system of the house, was controlled and monitored through a Clipsal C-Bus Building Management System. All the relevant parameters were monitored and logged using a JACE-6 controller at a one-minute sample rate.

The weather conditions, including ambient temperature, solar radiation and wind speed and direction, were monitored using a Davis Vantage Pro II Weather station and integrated through an RS232 connection to the C-Bus and JACE control units. Airflow was monitored using Siemens QVM62.1 air velocity sensors, located one third of the duct diameter from the duct centreline. These sensors had a stated accuracy of $\pm 0.2 \mathrm{~m} / \mathrm{s}+3 \%$ of measured values. Temperatures in the ductwork were measured using Clipsal C-Bus Digital Temperature Sensor Units $5104 \mathrm{DTSI}$ with a stated accuracy of $\pm 0.5^{\circ} \mathrm{C}$ in the temperature range of $-10^{\circ} \mathrm{C}$ $80^{\circ} \mathrm{C}$.

\subsection{Validation of the PVT Thermal Model}

The simulated PVT outlet air temperatures and the heat transfer rates under various air flow rates as well as the ambient air temperature, based on the IWEC July weather data of Sydney, are shown in Figure 10. 


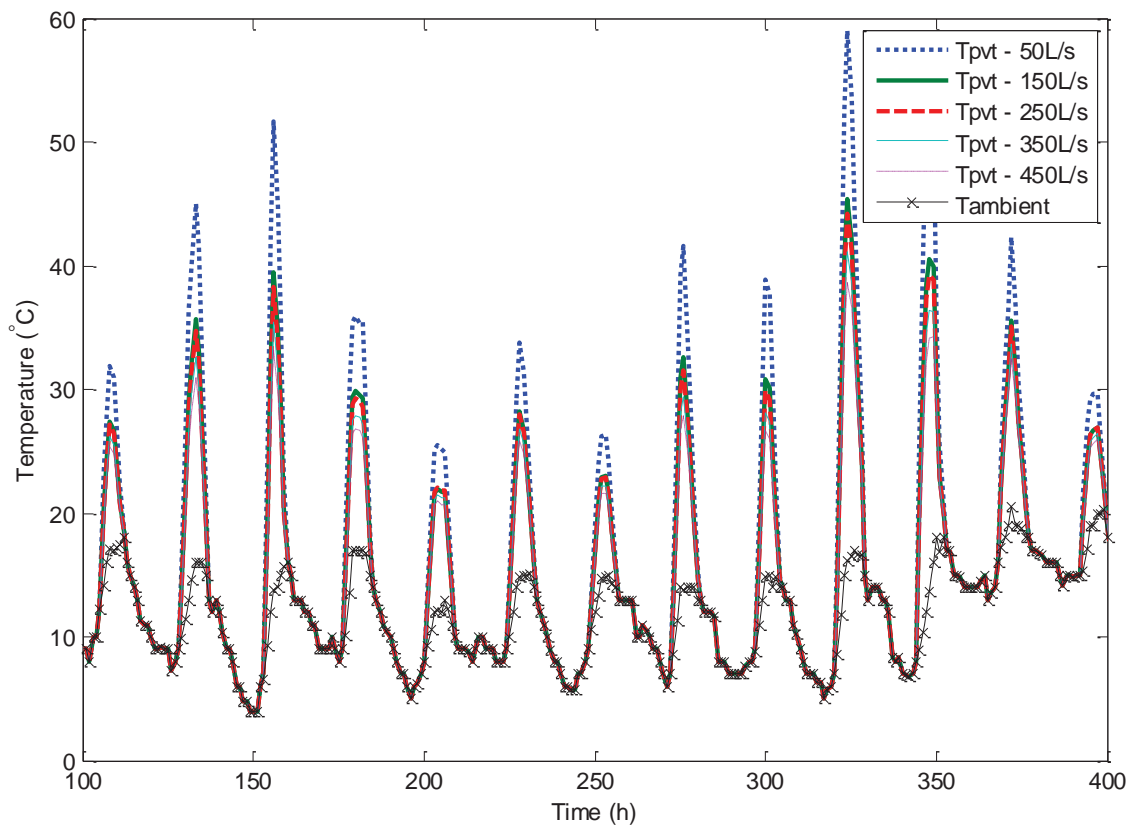

a) Temperature difference between ambient (inlet) air and PVT outlet as a function of time and flow rate through the PVT collector.

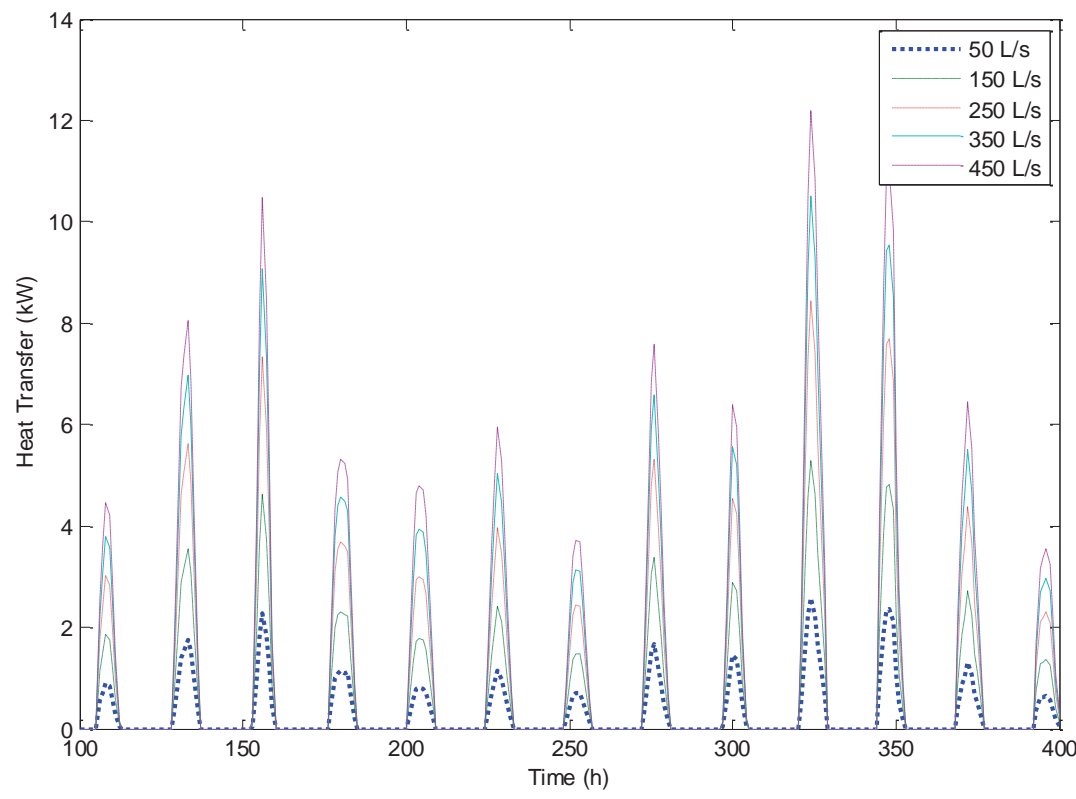

b) Heat transfer rate to air.

Figure 10: Temperature difference and heat transfer from the PVT collector under different air flow rates for July, Sydney, IWEC weather conditions. 
It can be seen that an increase in the airflow rate in the PVT collectors led to a decrease in the PVT outlet temperature and hence an increase in both the total heat transfer to the air and the thermal efficiency of the system. Simulations were also performed for the summer cooling case, where the sky temperature was calculated using (3.27). Using the Sydney IWEC weather data and considering the cloudiness factor, the total cooling was calculated to reach $1.5 \mathrm{~kW}$ when the airflow rate is $300 \mathrm{~L} / \mathrm{s}$.

The global horizontal radiation, ambient temperature, predicted PVT outlet temperatures and measured PVT outlet temperatures in Wollongong, Australia, for June 2014 are shown in Figure 11.

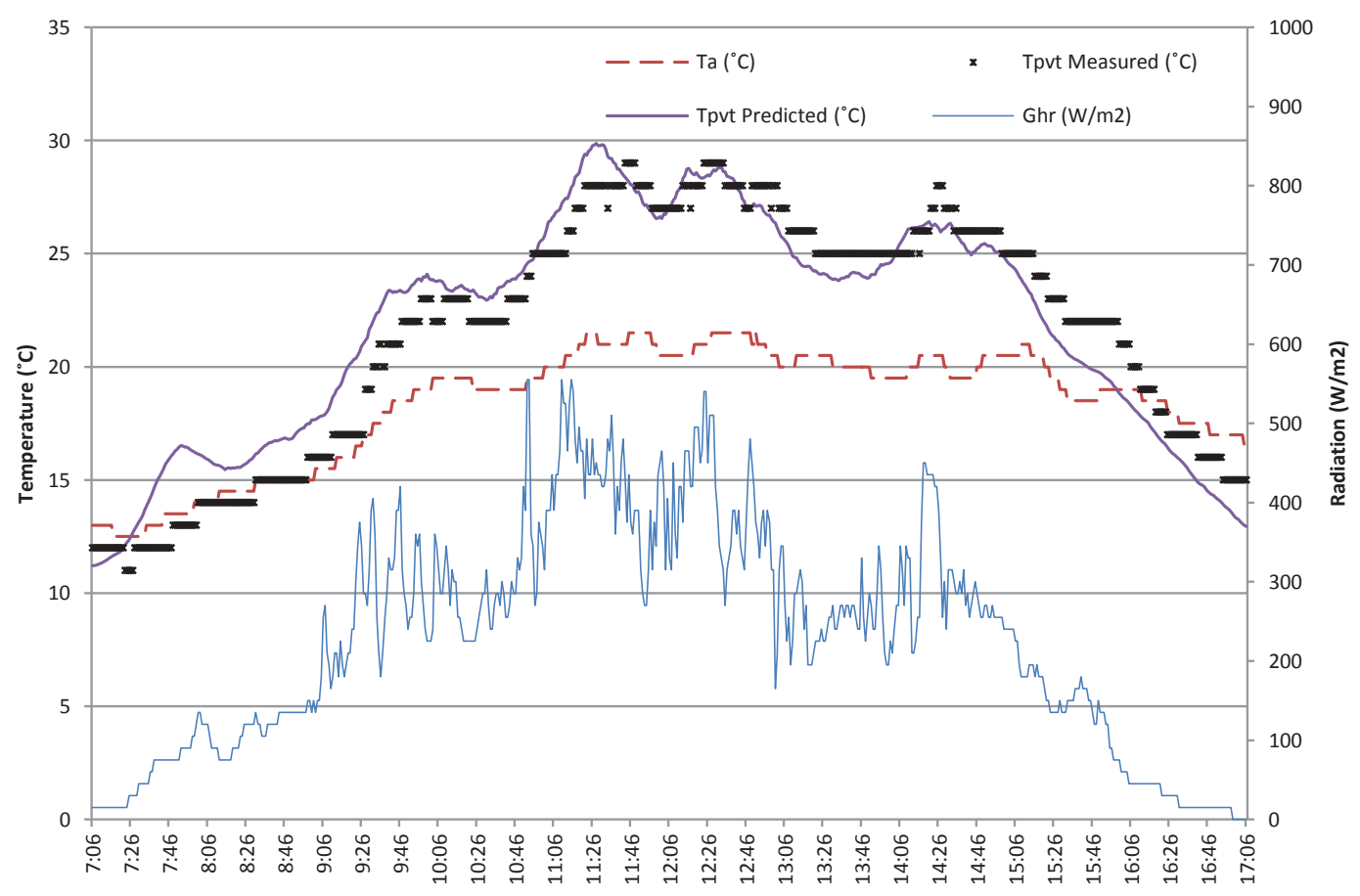

Figure 11: Comparison of the predicted PVT air outlet temperatures with the measured values (June 2014, Wollongong, Australia).

During these experimental tests the PVT airflow rate was maintained at $350 \mathrm{~L} / \mathrm{s}$. It can be seen that a very good agreement between the predicted PVT outlet temperatures and measured values was achieved. It is also seen that the experimental results lag the simulations 
by short time, less than five minutes, since the quasi-steady state thermal model of the PVT does not account for the relatively small thermal mass of the PVT collector.

A scatter plot of the predicted versus measured PVT outlet temperatures is shown in Figure 12, which provides substantive evidence that the simulations matched experiments with a linear regression coefficient $b=0.9911$ and $R^{2}{ }_{a d j}=0.9122$.

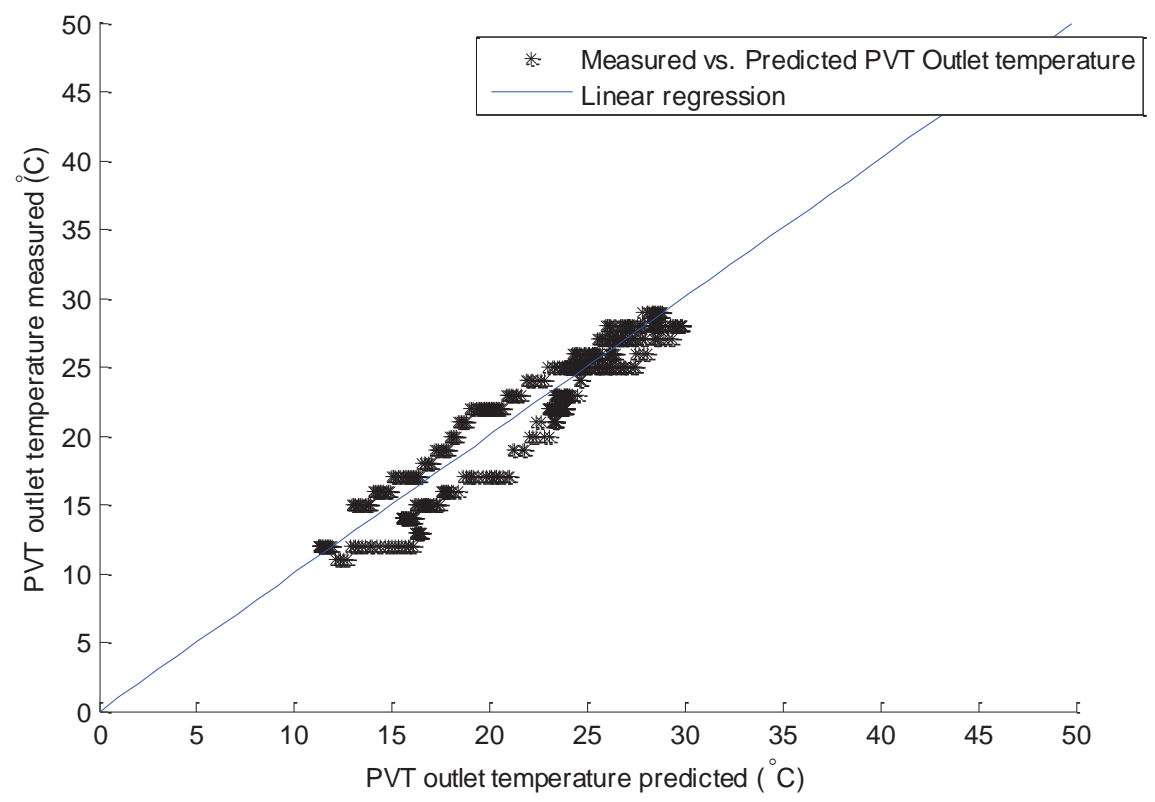

Figure 12: A scatter plot of measured and predicted PVT air outlet temperature data (June 2014, Wollongong, Australia).

This is considered to be a good result noting that the scatter in the data was in part due to the non-controlled and transient environment and that the data acquisition system has a course resolution on temperature due to the limitations of the residential building management system employed. In addition, the assumed negligible PVT collector thermal mass used in the thermal model also contributed somewhat to the scatter in the data.

The measured total electrical energy generated from the PVT roof, and that modelled as generated from both the north and south elevations of the PVT collector (viz Figure 5, using the published performance data of the CIGS solar panels and global insolation measured during field tests, are compared in Figure 13. 


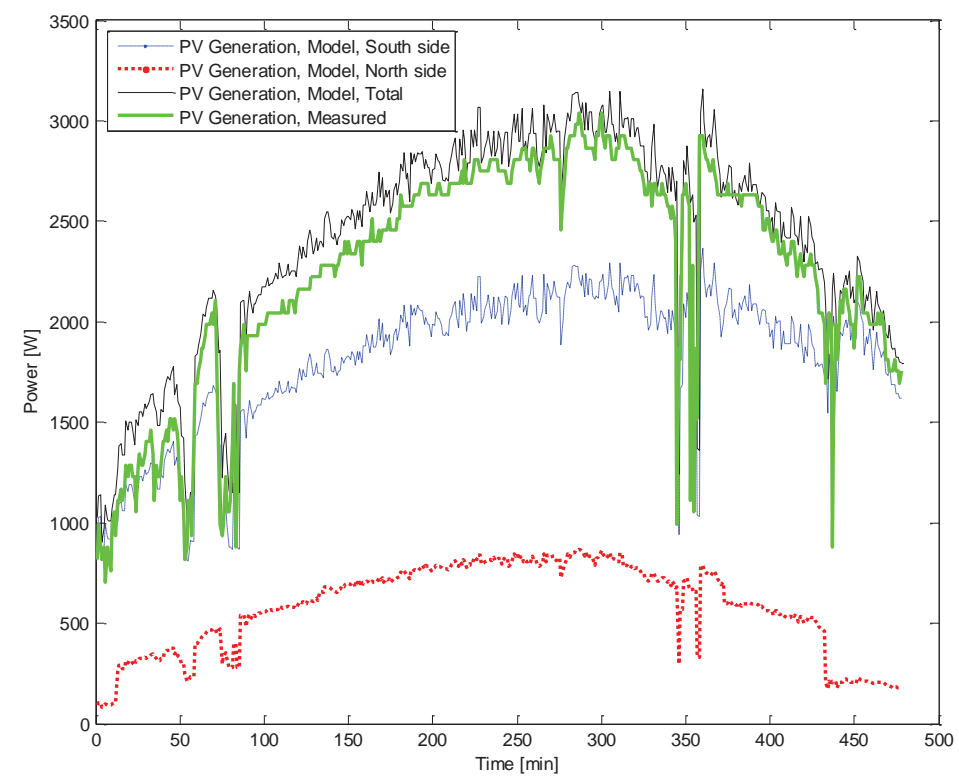

Figure 13: Predicted and measured PV electrical energy generation as a function of time (experiments conducted at Datong, China, during August 2013).

A scatter plot of the predicted versus measured PVT electrical generation is shown in Figure 14, with a linear regression coefficient $b=0.9947$, intercept a=-137 and $R_{\text {adj }}^{2}=$ 0.8904. This indicates a relatively good agreement between the two sets of data, with the model slightly over-predicting the electrical generation.

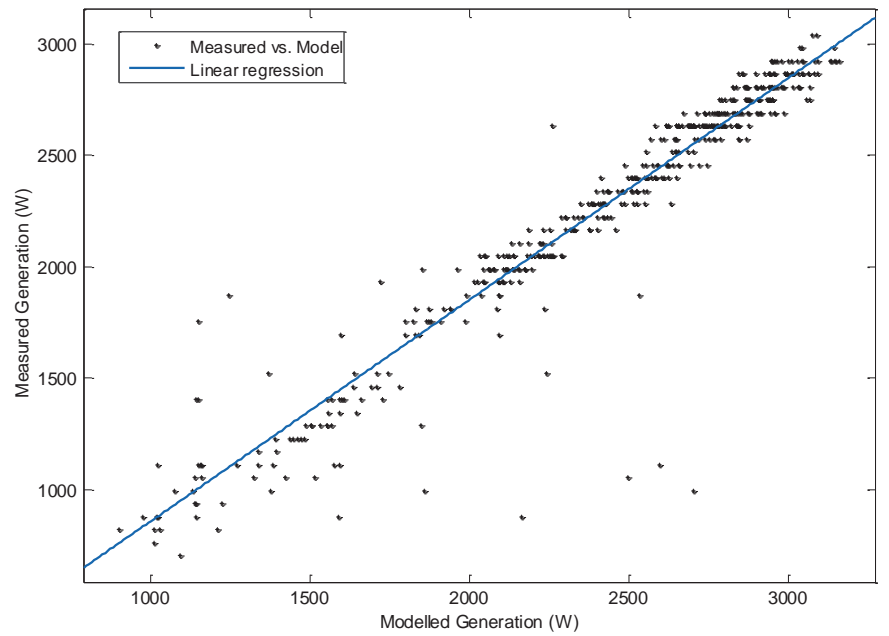

Figure 14: A scatter plot of measured and predicted PVT electrical generation 
The thermal efficiency, electrical efficiency and total efficiency of the PVT collector under the experimental tests at Datong, during August 2013, are shown in Figure 15.

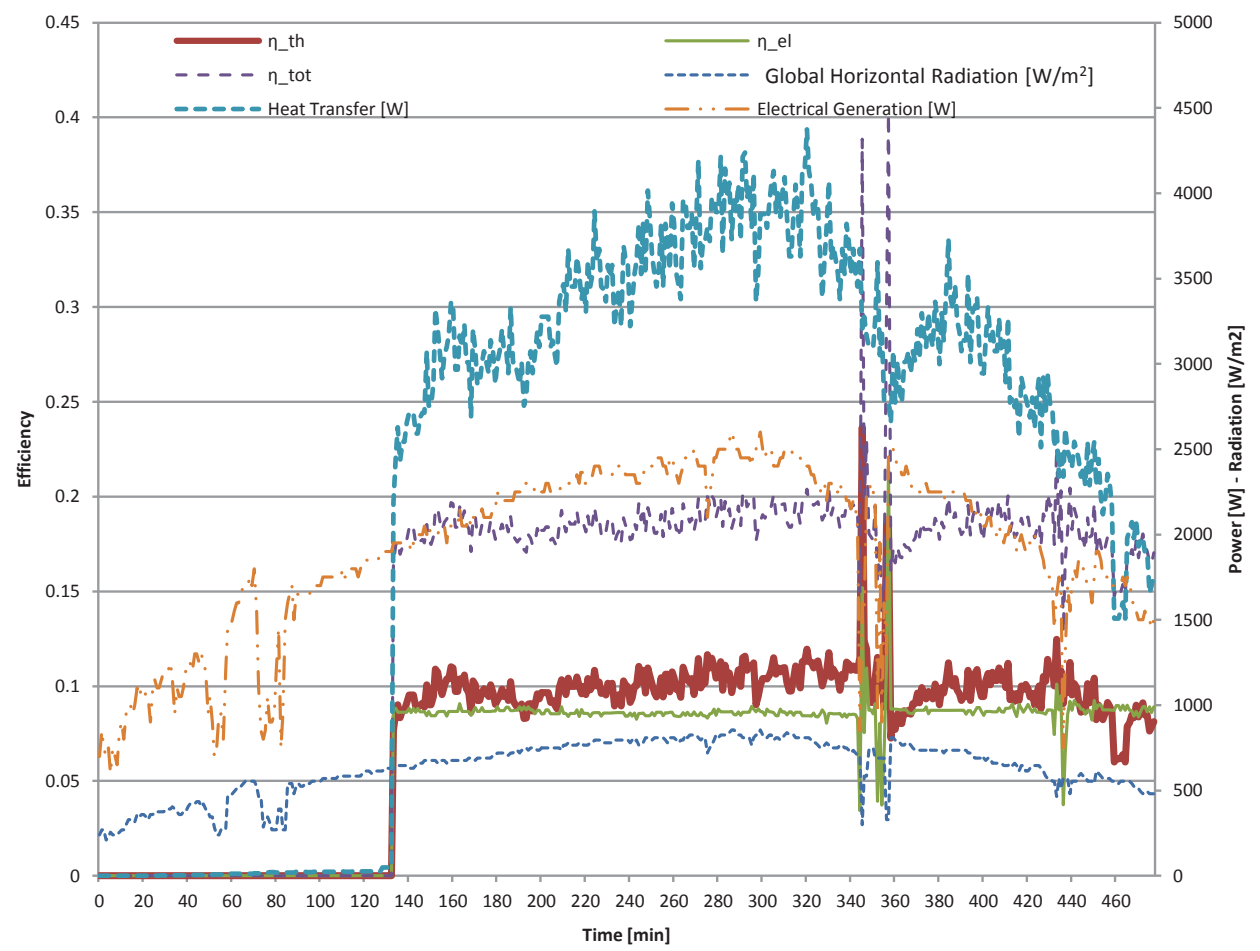

Figure 15: PVT efficiency as measured during testing August 2013 at Datong, China ( $\eta$ th, $\eta \_e l, \eta \_t o t$ are the PVT thermal, electrical and total efficiency, respectively).

It can be seen that the overall electrical efficiency of the PVT collector is relatively constant (i.e. 8.2\%) and consistent with the expected efficiency, considering that the published PV conversion efficiency was stated as $11.2 \%$ and the inverter efficiency taken to be $95 \%$. Even with a relatively low air flow (i.e. $160-170 \mathrm{~L} / \mathrm{s}$ ), the heat transfer to the air was as high as $4.0 \mathrm{~kW}$, equating to a thermal efficiency of around $9.0 \%$. The effect of extracting thermal energy from the PV panels was to increase the overall system efficiency to around $17 \%$.

5.3 Experimental validation of the PCM thermal model

The results of simulations of the performance of the PCM thermal storage unit are shown in Figure 16. The simulated air temperature profiles along the length of the PCM thermal 
storage unit under various airflow rates are shown as a function of distance from the inlet. As expected it was found that increasing the airflow rate led to higher heat transfer rates and higher outlet air temperature.

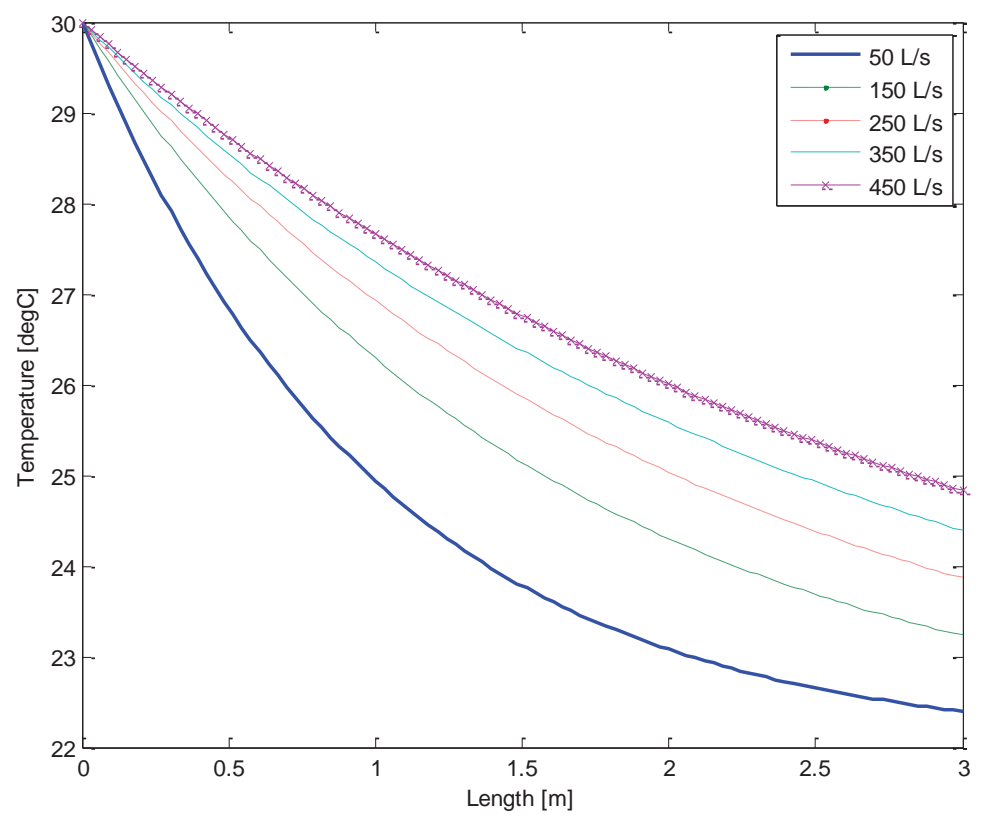

Figure 16: Modelled air temperature profile along the length of the PCM thermal storage unit under different airflow rates.

Experimental tests on the PCM thermal storage unit were carried out on a laboratoryscale test rig at the University of Wollongong, which was essentially a replica of the Illawarra Flame House PCM thermal store system with the same length of $3 \mathrm{~m}$, but with a reduced number of channels. The total mass of FlatIce ${ }^{\mathrm{TM}} \mathrm{PCM}$ in the lab-scale rig was $138 \mathrm{~kg}$, as compared to $693 \mathrm{~kg}$ in the Solar Decathlon house per se. The same equipment was used to measure and log the temperature and air flow data as that for the PVT tests described above, and a sample rate of 15 s was employed for the transient heating and cooling tests on the PCM store. 
The modelled and experimentally determined total $U A$ values for the heat exchanger under different flow rates are shown in Figure 17, where UA values for the experimental tests were found by dividing the total heat exchange of the fluid by the log-mean temperature difference (LMTD).

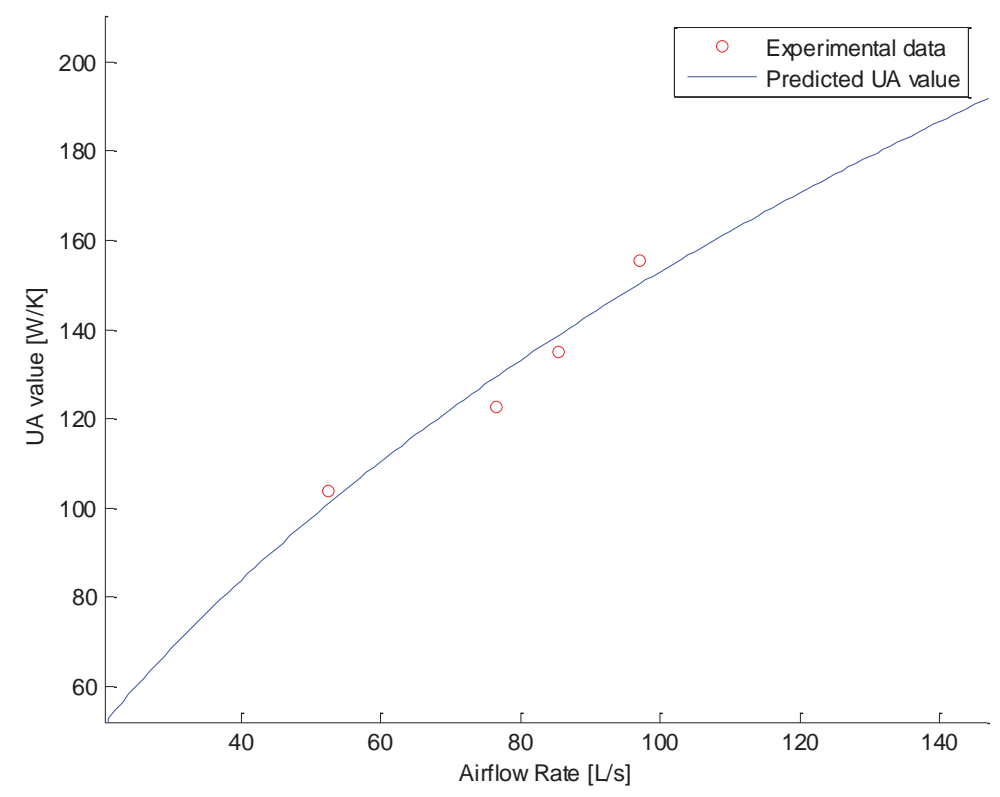

Figure 17: Comparison between modelled UA values (line) and experimental results (circles) of the laboratory-scale PCM thermal storage unit

\section{Optimisation of Operating Modes}

\subsection{PCM unit charging with PVT}

The models developed can be used for the optimisation of the various operating modes. For example the optimization of the PCM charging mode requires the control system to choose an optimal airflow rate that can maximise the benefit in terms of the heat stored in the PCM unit and how much energy is being used by the fan. In this study, a cost function as expressed in Equation (6.1) is used to maximize the amount of heat stored, considering that this would lead to certain electrical power consumption and an increase in the electrical generation that has to be somehow related to the heat transfer. 
$C(\dot{m})=P_{t h}(\dot{m})+\alpha_{c}\left(\Delta P_{e, g e n}(\dot{m})-P_{e, c o n s}(\dot{m})\right)$

$P_{t h}(\dot{m})=\rho \dot{V} c_{p}\left(T_{P V T}(\dot{m})-T_{P C M, o}(\dot{m})\right)$

Where, $\dot{V}$ is the flow rate of air flowing in the system, $c_{p}$ is the air specific heat capacity at $20^{\circ} \mathrm{C}, \rho$ is the density, $P_{t h}$ is the heat transfer rate into the PCM thermal storage unit as defined in Equation (3.2), $\Delta P_{e, g e n}$ is the increase in electrical generation due to the cooling of the solar panels, $\Delta P_{e, c o n s}$ is the power consumption of the fan to move the air into the system, $T_{p v t}$ and $T_{p c m, o}$ are respectively the PVT outlet temperature (which corresponds to the inlet temperature of the PCM if the thermal losses in the ducting can be considered negligible), $\alpha_{c}$ is a weighting factor for the electrical energy to increase its importance relatively to the thermal energy. The choice of this factor might be different from case to case, depending on the design objectives.

The simulated heat transfer, increased electrical generation of the PV panels and the electrical energy used by the fans are presented in Figure 18. This simulation was based on a single-sided PVT system in a winter heating scenario with the ambient temperature of $18^{\circ} \mathrm{C}$, indoor temperature of $25^{\circ} \mathrm{C}$, wind speed of $1 \mathrm{~m} / \mathrm{s}$. The radiation level on the tilted surface was $750 \mathrm{~W} / \mathrm{m}^{2}$.

The heat transfer into the PCM unit can then be correlated to the electrical power consumption of the fan and the increased electrical generation of the PV panels. Discontinuities in Figure 18 due to the changes in the heat transfer coefficient calculation between laminar flow and turbulent flow have been smoothed. 


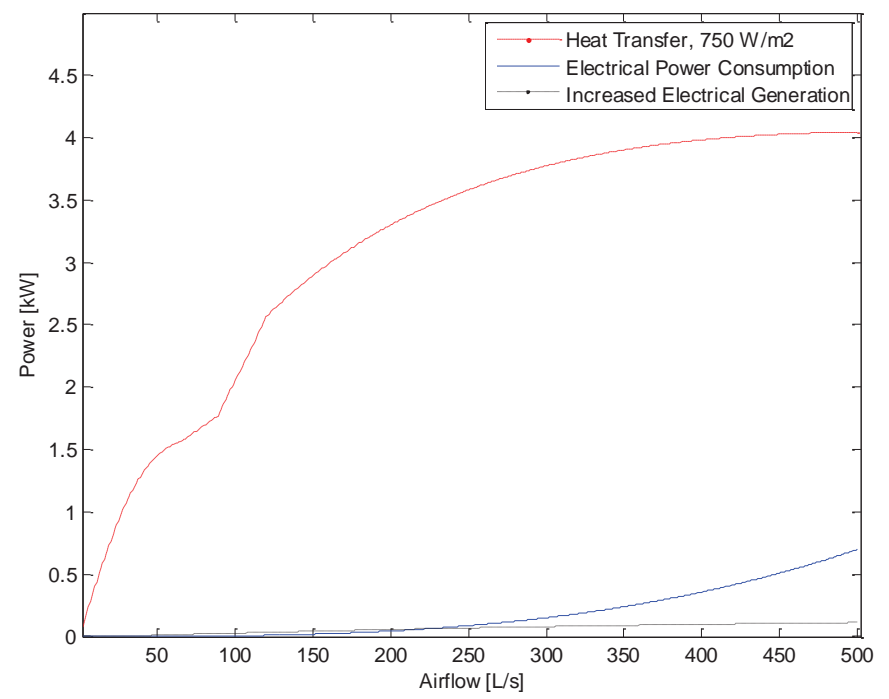

Figure 18: Heat transfer, increased electrical generation and electrical power consumption.

It is then possible to obtain the cost function curves (Equation 6.1) and identify the optimal airflow rate which corresponds to the maximum of the cost function under the different weather conditions (Figure 19). The discontinuities in this case due to the changes in the heat transfer coefficient calculation between laminar and turbulent flow have also been smoothed.

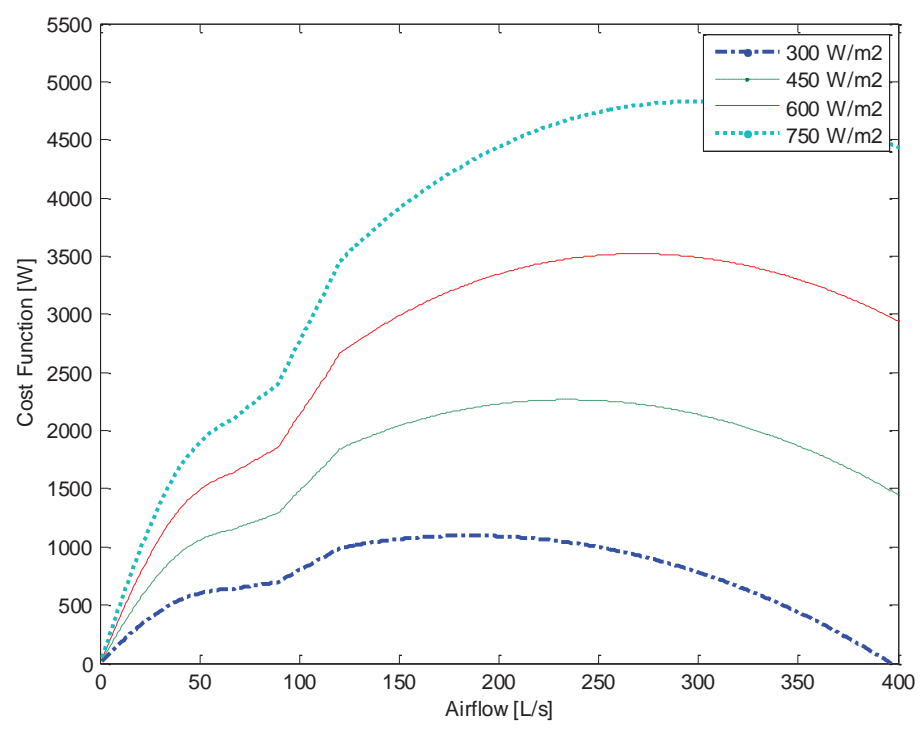

Figure 19: Evaluation of the cost function under different radiation levels. 


\subsection{Conditioning house with Direct PVT air supply}

The optimisation of the Direct PVT supply mode is very similar to that of the optimisation of the PCM charging mode, using the same cost function as presented in Equation (6.1). The calculation of the heating generated for the house is calculated as Equation (6.3).

$P_{t h}(\dot{m})=\rho \dot{V} c_{p}\left(T_{p v t}(\dot{m})-T_{\text {house }}\right)$

Where, $T_{\text {house }}$ is the average temperature of the house.

6.3 Conditioning house with PCM Discharging air supply

Similar to the PCM charging mode, the performance of the PCM discharging mode is highly dependent on the inlet temperature of the PCM thermal storage unit. In this operating mode, the inlet temperature is a mixture of the return air from the house and the fresh air from ambient. The ratio between the two air streams is dependent on the decisions taken at the design stage. Since there is no electrical generation involved, the optimisation of this working mode is to maximise the cost function below.

$C(\dot{m})=P_{t h}(\dot{m})-\alpha_{c}\left(P_{e, \text { cons }}(\dot{m})\right)$

Where $P_{t h}$ is the heat discharged from the PCM unit, defined as (6.5).

$P_{t h}(\dot{m})=\rho \dot{V} c_{p}\left(T_{P C M, o}(\dot{m})-T_{P C M, i}(\dot{m})\right)$

Where $T_{p c m, i}$ is the inlet temperature of the PCM unit, which is a mixture of the return air from the house and fresh air.

\section{Conclusions}

This paper outlined a modelling methodology for the thermal, hydraulic and electrical characteristics of a photovoltaic-thermal (PVT) system, and the thermal and hydraulic behaviour of an integrate Phase Change Material (PCM) thermal storage unit. This methodology is efficient and can be readily implemented in practice through the logic of an 
off-the-shelf residential Building Management System. In particular, the analytical solutions of the thermal models of the PVT and PCM systems guarantee the possibility of using these models for operational optimization with minimal computational effort.

The experimental field work and laboratory tests using a full-scale Solar Decathlon house and a laboratory-scale PCM thermal store test rig showed that this modelling methodology can provide sufficient accuracy for control purposes, despite its elegant simplicity. A simple optimisation methodology of the operating modes that involve these components is also presented.

Future work will be focused on the utilization of these component models for system optimization of the operation of the HVAC system incorporating a PVT collector, PCM thermal store, and conventional heat pump and air handling unit.

\section{Acknowledgements}

The authors would like to thank members of Team UOW and BlueScope for their assistance in the development of the PVT system, and Dr Josh Wall and colleagues of the Commonwealth Scientific and Industrial Research Organization (CSIRO) for their valuable advice and support in sourcing control and data acquisition equipment.

\section{Nomenclature}

$$
\begin{aligned}
& \alpha=\text { net thermal absorbtivity } \\
& \alpha_{c}=\text { a weighting factor for electrical and thermal energy } \\
& A_{c}=\text { cross sectional area }\left[\mathrm{m}^{2}\right] \\
& \beta=\text { surface slope [rad }] \\
& c_{p}=\text { specific heat of air }[\mathrm{J} / \mathrm{kg} \mathrm{K}] \\
& d=\text { PVT duct depth [m] } \\
& D_{h}=\text { hydraulic diameter }[\mathrm{m}] \\
& d n r=\text { direct normal radiation }\left[\mathrm{W} / \mathrm{m}^{2}\right]
\end{aligned}
$$




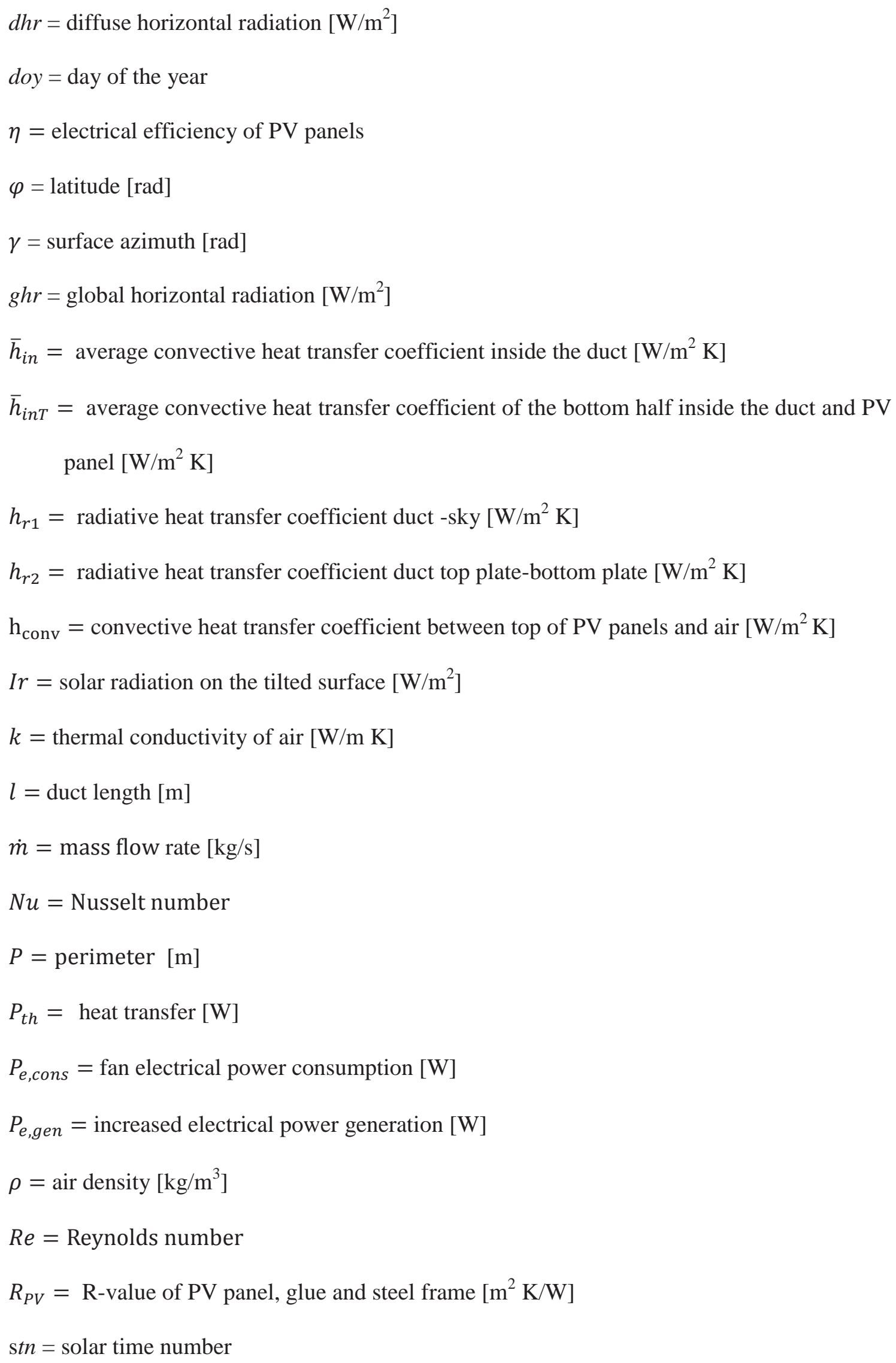


$T_{a m b}=$ ambient temperature $\left[{ }^{\circ} \mathrm{C}\right]$

$T_{P C M, i}=$ PCM unit inlet air temperature $\left[{ }^{\circ} \mathrm{C}\right]$

$T_{P C M, o}=$ PCM unit outlet air temperature $\left[{ }^{\circ} \mathrm{C}\right]$

$T_{\text {sky }}=$ sky temperature $\left[{ }^{\circ} \mathrm{C}\right]$

$T_{\text {space }}=$ indoor temperature $\left[{ }^{\circ} \mathrm{C}\right]$

$T_{d p}=$ dew point temperature $\left[{ }^{\circ} \mathrm{C}\right]$

$T_{\text {top }}=$ top plate temperature $\left[{ }^{\circ} \mathrm{C}\right]$

$T_{\text {bot }}=$ bottom plate temperature $\left[{ }^{\circ} \mathrm{C}\right]$

$T_{P V T}=$ PVT outlet air temperature $\left[{ }^{\circ} \mathrm{C}\right]$

$u=$ specific internal energy $[\mathrm{kJ} / \mathrm{kg}]$

$U_{\text {int }}=\mathrm{U}$-value from lower inside surface of duct to inside building $\left[\mathrm{W} / \mathrm{m}^{2} \mathrm{~K}\right]$

$U_{\text {ext }}=\mathrm{U}$-value from bottom surface of PV panels to ambient [W/ $\left./ \mathrm{m}^{2} \mathrm{~K}\right]$

$\dot{V}=$ volumetric flow rate $\left[\mathrm{m}^{3} / \mathrm{s}\right]$

$V_{w}=$ wind speed $[\mathrm{m} / \mathrm{s}]$

$v=$ viscosity of air $\left[\mathrm{m}^{2} / \mathrm{s}\right]$

$w=$ PVT duct width $[\mathrm{m}]$

$x=$ distance from the inlet $[\mathrm{m}]$ 


\section{References}

[1] Z. Ma, P. Cooper, D. Daly, L. Ledo, Existing building retrofits: Methodology and stateof-the-art, Energy and Buildings 55 (2012) 889-902.

[2] R. Baetens, B.P. Jelle, A. Gustavsen, Phase change materials for building applications: A state-of-the-art review, Energy and Buildings 42 (2010) 1361-1368.

[3] W. Lin, Z. Ma, M.I. Sohel, P Cooper, Development and evaluation of a ceiling ventilation system enhanced by solar photovoltaic thermal collectors and phase change materials, Energy Conversion and Management 88 (2014) 218-230.

[4] J.J. Jurinak, S.I. Abdel-Kalik, On the performance of air-based solar heating systems utilizing phase-change energy storage, Energy 4 (1979) 503-522.

[5] J.J. Jurinak, S.I. Abdel-Kalik, Properties optimization for phase-change energy storage in air based solar heating systems, Solar Energy 21 (1978) 377-383.

[6] J.J. Jurinak, S.I. Abdel-Kalik, Sizing phase change energy storage units for air-based solar heating systems, Solar Energy 22 (1979) 355-359.

[7] M. Pomianowskia, P. Heiselberga, Y. Zhang, Review of thermal energy storage technologies based on PCM application in buildings, Energy and Buildings 67 (2013) 56-69. [8] N. Zhu, S. Wang, X. Xu, Z. Ma, A simplified dynamic model of building structures integrated with shaped-stabilized phase change materials, International Journal of Thermal Sciences 49 (2010) 1722-1731.

[9] Y. Chen, A.K. Athienitis, K. Galal, Modeling, Design and thermal performance of a BIPV/T system thermally coupled with a ventilated concrete slab in a low energy solar house: Part 1, BIPV/T system and house energy concept, Solar Energy 84 (2010) 1892-1907.

[10] Y. Chen, A.K. Athienitis, K. Galal, Modeling, Design and thermal performance of a BIPV/T system thermally coupled with a ventilated concrete slab in a low energy solar house: Part 2, ventilated concrete slab, Solar Energy 84 (2010) 1908-1919. 
[11] S. Pantic, L. Candanedo, A.K. Athienitis, Modeling of energy performance of a house with three configurations of building-integrated photovoltaic/thermal systems, Energy and Buildings 42 (2010) 1779-1789.

[12] Ursula Eicker, Antoine Dalibard, Photovoltaic-thermal collectors for night radiative cooling of buildings, Solar Energy 85 (2011) 1322-1335.

[13] www.pcmproducts.net

[14] Petros J. Axaopoulos, Emmanouil D. Fylladitakis, Performance and economic evaluation of a hybrid photovoltaic/thermal solar system for residential applications, Energy and Buildings 65 (2013) 488-496.

[15] ASHRAE Handbook - Fundamentals, 2009. Heat Transfer (Chapter 3).

[16] P. Berdahl, R. Fromberg, The thermal radiance of clear skies, Solar Energy 29 (1982) 299-314.

[17] J.A. Duffie, W.A. Beckman, Solar Engineering of Thermal Processes, 2013.

[18] G. Mihalakakou, A. Ferrante, J.O. Lewis, The cooling potential of a metallic nocturnal radiator, Energy and Buildings 28 (1998) 251-256.

[19] Bagiorga, G. Mihalakakou, Experimental and theoretical investigation of a nocturnal radiator for space cooling, H.S. Renewable Energy 33 (2008) 1220-1227.

[20] E. Skoplaki, J.A. Palyvos, On the temperature dependence of photovoltaic module electrical performance: A review of efficiency/power correlations, Solar Energy 83 (2009) $614-624$. 


\section{Figure Captions}

Figure 1: Team UOW 'Illawarra Flame' Solar Decathlon house located at the University of

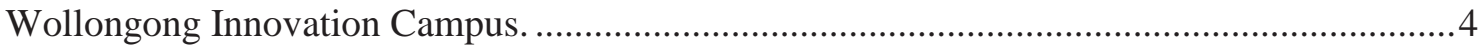

Figure 2: Schematic of the solar-assisted HVAC system where the symbols represent the following: S/A supply air, O/A outside air, R/A return air, E/A exhaust air, F fan and D

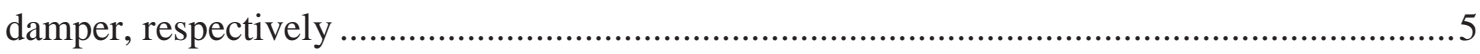

Figure 3: Illustration of a) HVAC system conditioning modes and b) HVAC system PVT modes 6

Figure 4: Overview of the PVT collector geometry as implemented on the Illawarra Flame Solar Decathlon House. 8

Figure 5: Photovoltaic thermal (PVT) collectors implemented on the roof of the Illawarra Flame Solar Decathlon house. 9

Figure 6: Thermal resistance network model of the heat exchange at a given cross-section of the PVT collector. 10

Figure 7: Air flow resistance network showing flow elements/resistances for flow branches connected to the air collection manifold. V1, V2, etc. represent PVT ducts and H1, H2, etc.

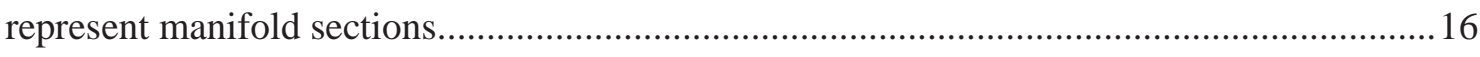
Figure 8: Pressure-airflow characteristic of the 'Illawarra Flame' Solar Decathlon house PVT

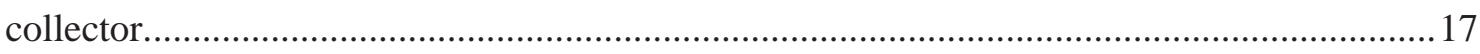

Figure 9: Pressure drop-airflow through the PCM thermal storage unit. ...............................20

Figure 10: Temperature difference and heat transfer from the PVT collector under different air flow rates for July, Sydney, IWEC weather conditions...............................................22 Figure 11: Comparison of the predicted PVT air outlet temperatures with the measured values (June 2014, Wollongong, Australia). 23 
Figure 12: A scatter plot of measured and predicted PVT air outlet temperature data (June

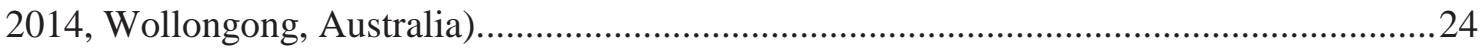

Figure 13: Predicted and measured PV electrical energy generation as a function of time (experiments conducted at Datong, China, during August 2013)........................................25

Figure 14: A scatter plot of measured and predicted PVT electrical generation .....................25

Figure 15: PVT efficiency as measured during testing August 2013 at Datong, China ( $\eta$ th, $\eta \_$el, $\eta \_$tot are the PVT thermal, electrical and total efficiency, respectively)........................26 Figure 16: Modelled air temperature profile along the length of the PCM thermal storage unit

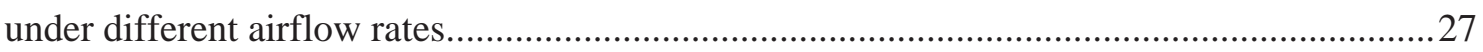

Figure 17: Comparison between modelled UA values (line) and experimental results (circles) of the laboratory-scale PCM thermal storage unit .............................................................28

Figure 18: Heat transfer, increased electrical generation and electrical power consumption. 30 Figure 19: Evaluation of the cost function under different radiation levels. .30 